\title{
Achievement of renal anemia KDIGO targets by two different clinical strategies - a European hemodialysis multicenter analysis
}

Maciej Drozdz ${ }^{1}$, André Weigert ${ }^{2,3,4}$, Fatima Silva², João Frazão ${ }^{2,5,6}$, Abdulkareem Alsuwaida ${ }^{7,8}$, Mahesh Krishnan ${ }^{9}$, Werner Kleophas ${ }^{10,11}$, Szymon Brzosko ${ }^{12,13}$, Fredrik K. Johansson ${ }^{14}$ and Stefan H. Jacobson ${ }^{15^{*}}$

\begin{abstract}
Background: The optimal treatment algorithm for iron therapy and the use of erythropoiesis-stimulating agents (ESA) in anemic hemodialysis (HD) patients has not been established. Hemoglobin ( $\mathrm{Hb}$ ) target levels can be achieved through more frequent intravenous (IV) iron use with lower ESA dose, or with less iron dosing but higher ESA. ESA therapy to correct anemia may result in severe arterial and venous thrombotic complications and the evidence base evaluating hard clinical outcomes related to the use of IV iron is sparse.

Methods: A total of 1247 maintenance HD patients from 12 dialysis centers in Portugal $(n=730)$ and Poland $(n=$ 517) were considered. We assessed achievement of KDIGO renal anemia targets with focus on treatment strategies, which typically differ between countries. In Poland the use and dose of IV iron was 35-72\% higher than that in Portugal ( $p<0.001$ ) during three consecutive months; use and dose of ESA was 61\% higher in Portugal (5034 vs $3133 \mathrm{IU}$ (adjusted)/week, $p<0.001$ ).

Results: Mean Hb concentration was similar (11.0 vs $11.0 \mathrm{~g} / \mathrm{dL}$ ) in patients treated in both countries and the proportion of patients within KDIGO anemia target was $69.5 \%$ in Poland vs $65.8 \%$ in Portugal (NS). Ferritin and TSAT levels and the proportion of patients with TSAT $>20$ and $>50 \%$ were both significantly higher in patients in Poland (88.8 and 14.6\%) than in Portugal (76.3 and 5.7\% respectively, $\mathrm{p}<0.001)$. Significantly more patients in Poland had a ferritin concentration $>800 \mu \mathrm{g} / \mathrm{L}(35.6 \%)$ compared to Portugal $(15.8 \%, p<0.001)$. The ESA resistance index (ERI) was significantly higher in patients treated in Portugal $(p<0.001)$. Correlation analyses showed confounding by treatment indication in unadjusted models. Multiple and logistic regression analyses showed that with ferritin within KDIGO recommended range of $200-800 \mu \mathrm{g} / \mathrm{L}$ the odds for $\mathrm{Hb}$ within guidelines increased significantly. Annual gross mortality was 16\% in Poland and 13\% in Portugal (NS); there were no differences in cause-specific mortality.
\end{abstract}

Conclusions: Administration of high doses of IV iron in routine clinical HD practice may not be associated with considerable harm. However, large randomized controlled trials are needed to provide absolute evidence of iron safety.

Keywords: Anemia, Erythropoiesis-stimulating agent, Ferritin, Hemodialysis, Hemoglobin, Iron, Mortality, TSAT

\footnotetext{
* Correspondence: Stefan.Jacobson@sll.se

${ }^{15}$ Division of Nephrology, Department of Clinical Sciences, Karolinska

Institutet, Danderyd University Hospital, Stockholm, Sweden

Full list of author information is available at the end of the article
}

(c) The Author(s). 2019 Open Access This article is distributed under the terms of the Creative Commons Attribution 4.0 International License (http://creativecommons.org/licenses/by/4.0/), which permits unrestricted use, distribution, and reproduction in any medium, provided you give appropriate credit to the original author(s) and the source, provide a link to the Creative Commons license, and indicate if changes were made. The Creative Commons Public Domain Dedication waiver (http://creativecommons.org/publicdomain/zero/1.0/) applies to the data made available in this article, unless otherwise stated. 


\section{Background}

Anemia in patients on hemodialysis (HD) significantly impairs quality of life. Several previous studies have shown that more severe anemia is associated with higher risk of left ventricular hypertrophy, cardiovascular events, transfusion-related infections, hospitalization and death $[1,2]$. Anemia management in HD patients has focused on the use of erythropoiesis-stimulating agents (ESA) and iron therapy, but, following concerns regarding the safety of using high doses of ESA to meet aggressive $\mathrm{Hb}$ targets that were raised by clinical trials such as NHS [3], CREATE [4], CHOIR [5, 6] and TREAT [7],interest in the use of intravenous (IV) iron therapy has increased $[8,9]$.

Many patients on HD are in negative iron balance because of poor appetite and reduced dietary intake of iron, reduced absorption from the gut, and increased gastrointestinal iron losses. Hemodialysis- and laboratory test-related blood loss vary substantially over time and among patients and are also influenced by anticoagulant and antiplatelet therapy $[10,11]$.

Currently, serum iron, serum ferritin and transferrin saturation (TSAT) are commonly assessed as markers of iron metabolism in clinical practice. However, these indicators are far from optimal as they can be influenced by malnutrition and inflammation, both of which are common in patients on HD [12, 13]. IV iron administration is often required to attain iron repletion and increases in $\mathrm{Hb}$ values in such patients, and also to optimize the treatment response to ESA. However, concerns have been raised regarding the safety of iron compounds due to the possibility of iron overload, oxidative stress, cardiovascular disease, hypersensitivity reactions, and exacerbation of infection $[14,15]$.

In addition, ESA therapy in patients on HD may result in many adverse clinical consequences, especially stroke, venous thromboembolic disease, and vascular access thrombosis [16] and some patients do not respond adequately to ESA $[17,18]$.

Currently, the evidence base relating to the use of IV iron in combination with ESA is limited, and the effects of IV iron on clinical outcomes, like death and major health events remain uncertain.

The Kidney Disease Improving Global Outcomes (KDIGO) clinical practice guideline on anemia management [19] proposes a broader use of iron therapy in HD patients, including higher values of TSAT and ferritin at which iron therapy should be initiated or discontinued. Since the publication of the guideline, there have been significant changes in anemia management practices in in many countries, with a notable shift towards lower $\mathrm{Hb}$ levels, lower ESA doses and greater use of IV iron $[8,9]$. Data from the Dialysis Outcomes and Practice Patterns Study (DOPPS) have shown progressive increases in serum ferritin in recent years, with nearly $40 \%$ of the HD population in the US having ferritin levels greater than $800 \mathrm{ng} / \mathrm{mL}$. Similar trends have been observed in some European countries [8].

In the present European multicenter analysis, we compared clinical practices and strategies to achieve the KDIGO targets for renal anemia in a large cohort of patients on HD in 12 DaVita centers in Portugal and Poland as part of our continuous quality improvement efforts. In addition, annual mortality was analyzed and compared between countries and centers.

\section{Methods}

We included 1247 patients on maintenance HD from DaVita Portugal (5 dialysis centers, $n=730$, mean age $69 \pm 14$ years (SD), $40 \%$ females) and DaVita Poland (7 dialysis centers, $n=517$, mean age $67 \pm 15$ years, $47 \%$ females) in an analysis of the achievement of KDIGO renal anemia targets and focused on treatment strategies, which by tradition and socioeconomic factors differ in the two countries (Table 1 and Table 2). The patient cohort includes all prevalent HD patients treated at all DaVita facilities in Portugal and Poland, and thus represent a "real world" clinical observation from two regions in Europe that previously haven't been included in the global DOPPS analysis.

Demographic data and information on practices were collected during the same month in all patients in both countries. Monthly iron doses were recorded during three consecutive months in both regions. Blood samples were collected monthly or quarterly in accordance with international clinical guidelines (European best practice guidelines, KDIGO guidelines) and results were reviewed by the national chief medical officer and discussed with the European chief medical officer monthly.

The most common cause of end-stage renal disease (ESRD) in both Portugal (42\%) and Poland (35\%) was classified as "unknown" or "other". Diabetes mellitus, nephrosclerosis and glomerulonephritis were the causes of ESRD in 30, 10 and $11 \%$ of HD patients in Portugal; the corresponding percentages were 25,13 and $20 \%$ for patients in Poland $(p<0.001)$.

All laboratory analyses were performed at local laboratories according to validated and recommended routine procedures. Intact parathyroid hormone $(\mathrm{PTH})$ was measured. spKt $/ \mathrm{V}=$ single pool $\mathrm{Kt} / \mathrm{V}$. The correction factor for darbepoietin to epoetin doses was 250. The erythropoiesis-stimulating agent resistance index (ERI) was defined as the weight-adjusted weekly ESA dose divided by the hemoglobin value $[\mathrm{IU} / \mathrm{kg} /(\mathrm{g} / \mathrm{dl})]$.

The study was approved by the Regional Ethics committee in Stockholm, located at the Karolinska Institutet, Stockholm, Sweden. All clinical and laboratory patient data were sent deidentified from the respective country 
Table 1 Demographics and laboratory profile

\begin{tabular}{|c|c|c|c|c|}
\hline mean (SD) & All & Portugal & Poland & $p^{*}$ \\
\hline Number of patients & 1247 & 730 & 517 & - \\
\hline Age (years) & $68(14)$ & $69(14)$ & $67(15)$ & $<0.01$ \\
\hline Time on dialysis (months) & $60.7(58.5)$ & $66.1(63.7)$ & $53.2(49.4)$ & $<0.001$ \\
\hline Weight post dialysis (kg) & $70.2(22.1)$ & $68.2(13.8)$ & $74.3(29.8)$ & $<0.001$ \\
\hline $\mathrm{BMI}\left(\mathrm{kg} / \mathrm{m}^{2}\right)$ & $26.0(7.8)$ & $25.2(4.7)$ & $27.1(10.7)$ & $<0.001$ \\
\hline Hemoglobin (g/dL) & $11.0(1.3)$ & $11.0(1.3)$ & $11.0(1.3)$ & N.S. \\
\hline TSAT (\%) & $31.3(14.5)$ & $28.5(12.9)$ & $35.3(15.5)$ & $<0.001$ \\
\hline Ferritin $(\mu \mathrm{g} / \mathrm{L})$ & $605.4(491.5)$ & $497.9(344.3)$ & $757.1(613.5)$ & $<0.001$ \\
\hline Weekly dose of ESA (corrected) (U) & $4306(5134)$ & $5154(6077)$ & $3133(3068)$ & $<0.001$ \\
\hline Iron dose (mg per month 1) & $176(172)$ & $143(176)$ & $246(141)$ & $<0.001$ \\
\hline Iron dose (mg per month 2) & $164(164)$ & $147(173)$ & $198(141)$ & $<0.001$ \\
\hline Iron dose (mg per month 3) & $176(180)$ & $151(187)$ & $230(150)$ & $<0.001$ \\
\hline spKt/N & $1.8(0.4)$ & $2.0(0.4)$ & $1.6(0.3)$ & $<0.001$ \\
\hline URR (\%) & $77.5(8.1)$ & $79.9(6.7)$ & $74.2(8.7)$ & $<0.001$ \\
\hline Weekly treatment time (min) & $729(56)$ & $724(53)$ & $737(55)$ & $<0.001$ \\
\hline Treated blood volume $(\mathrm{L} / \mathrm{kg})$ & $1.34(0.32)$ & $1.45(0.35)$ & $1.20(0.24)$ & $<0.001$ \\
\hline IDBWG (kg) & $2.3(1.7)$ & $1.9(1.7)$ & $2.9(1.5)$ & $<0.001$ \\
\hline Albumin $(g / L)$ & $40.7(3.7)$ & $40.4(3.4)$ & $41.2(3.6)$ & N.S. \\
\hline Calcium (mg/dL) & $8.8(0.7)$ & $8.9(0.6)$ & $8.7(0.8)$ & $<0.001$ \\
\hline Phosphorus (mg/dL) & $4.4(1.4)$ & $4.1(1.2)$ & $4.7(1.5)$ & $<0.001$ \\
\hline Intact PTH (pg/mL) & $563(531.5)$ & $561(518.0)$ & $565(551.2)$ & N.S. \\
\hline
\end{tabular}

"Students t-test between hemodialysis facilities in countries

N.S. = Not significant

Abbreviations: BMI body mass index, TSAT transferrin saturation, ESA erythropoiesis-stimulating agents, spKt/N single pool Kt/V, URR urea reduction ratio, IDBWG interdialytic body weight gain, PTH parathyroid hormone

and all statistical analyses were performed by $\mathrm{SHJ}$ and FKJ at the Department of Clinical Sciences at the Karolinska Institutet, Stockholm, Sweden.

\section{Statistical analyses}

Statistical analyses were done using IBM SPSS Statistics version 25 at the Unit for medical statistics at the Karolinska Institutet, Stockholm, Sweden. All values are presented as mean or median and comparisons between countries were performed using Student's t-test and Chi-2 analysis as appropriate. Correlations were done using Pearson correlation and multiple regression and logistic regression analyses were used to adjust for covariates. Results are given as odds ratio with additional $p$-value and beta coefficient with $p$-value. Since we do not have information on the exact date of death for each individual patient in this study, we were unable to assess hazard ratios using Cox regression analysis. A $p$-value $<0.05$ was considered statistically significant.

\section{Results}

\section{Demographic and laboratory profiles}

Table 1 and Table 2 show demographic and clinical mean (SD) values and category (\%) data for all patients as well as for patients from the respective country. HD patients treated at centers in Portugal were significantly older (69 vs 67 years), had longer dialysis vintage (66 vs 53 months), lower body weight and BMI than the corresponding patients treated in Poland (Table 1). A high Charlson comorbidity index, $7-12$ or $>12$ was significantly more frequent among HD patients at facilities in Portugal than in patients in Poland $(p<0.001$, Table 2$)$. Serum albumin was 40 (3) g/L and 41 (4) g/L in units in Portugal and Poland, respectively (NS), but the proportion of patients with a serum albumin $\geq 35 \mathrm{~g} / \mathrm{L}$ was significantly higher in Portugal (95\%) than in Poland (82\%, $p<0.001$, Table 2). Serum phosphorus was significantly higher $(p<0.001)$ and the proportion of patients with serum phosphorus $\leq 5.5 \mathrm{mg} / \mathrm{dL}$ significantly lower $(p<0.001)$ in patients in Poland than in Portugal, but there were no significant differences in intact PTH (Table 1 and Table 2).

\section{Prescription of hemodialysis}

In facilities in Portugal, almost all patients had hemodiafiltration (HDF) while in Poland 91\% had conventional hemodialysis (100\% high flux membranes) and $9 \%$ had HDF ( $p<0.001$, Table 2). An AV fistula (AVF) was used as a vascular access in $77 \%$ of patients in centers in Portugal and in $76 \%$ of patients in Poland (NS, Table 2). 
Table 2 Patient characteristics

\begin{tabular}{|c|c|c|c|c|}
\hline & $\begin{array}{l}\text { All } \\
(\%)\end{array}$ & $\begin{array}{l}\text { Portugal } \\
\text { (\%) }\end{array}$ & $\begin{array}{l}\text { Poland } \\
\text { (\%) }\end{array}$ & $p^{*}$ \\
\hline Hemoglobin $10-12 \mathrm{~g} / \mathrm{dL}$ & 67.3 & 65.8 & 69.5 & N.S. \\
\hline Hemoglobin $>12 \mathrm{~g} / \mathrm{dL}$ & 15.2 & 15.3 & 15.1 & N.S. \\
\hline Ferritin $\geq 200 \mu \mathrm{g} / \mathrm{L}$ & 84.4 & 82.9 & 86.6 & N.S. \\
\hline Ferritin $\geq 800 \mu \mathrm{g} / \mathrm{L}$ & 24.0 & 15.8 & 35.6 & $<0.001$ \\
\hline TSAT $\geq 20 \%$ & 81.5 & 76.3 & 88.8 & $<0.001$ \\
\hline TSAT $\geq 50 \%$ & 9.4 & 5.7 & 14.6 & $<0.001$ \\
\hline Treatment with ESA & 76 & 78 & 74 & 0.056 \\
\hline Type of ESA & & & & N.S. \\
\hline Darbepoietin & 24 & 22 & 26 & \\
\hline Epoetin beta & 76 & 78 & 74 & \\
\hline Route of ESA administration & & & & $<0.001$ \\
\hline Intravenous & 64.5 & 99.8 & 11.5 & \\
\hline Subcutaneous & 35.5 & 0.2 & 88.5 & \\
\hline ESA administration, frequency & & & & $<0.001$ \\
\hline No ESA & 23.6 & 21.7 & 26.3 & \\
\hline Every other week & 0.4 & 0.7 & 0 & \\
\hline Once per week & 15.0 & 2.1 & 33.2 & \\
\hline Twice per week & 15.9 & 11.1 & 22.6 & \\
\hline Three times per week & 45.1 & 64.5 & 18.0 & \\
\hline Dialysis modality & & & & $<0.001$ \\
\hline HDF & 46.6 & 91.4 & 0 & \\
\hline$H D$ & 53.4 & 8.6 & 100 & \\
\hline $\mathrm{spKt} / \mathrm{N}>1.2$ & 97.3 & 98.5 & 95.6 & 0.003 \\
\hline URR $\geq 70 \%$ & 90.8 & 95.4 & 84.4 & $<0.001$ \\
\hline Treatment time $\geq 12 \mathrm{~h} /$ week & 93.8 & 94.0 & 93.6 & N.S. \\
\hline Prescribed $\mathrm{Qb} \geq 300 \mathrm{~mL} / \mathrm{min}$ & 94.1 & 97.4 & 89.4 & $<0.001$ \\
\hline Treated blood volume $\geq 1 \mathrm{~L} / \mathrm{kg}$ body weight & 90.0 & 95.7 & 81.9 & $<0.001$ \\
\hline CVC (\%) & 16.5 & 14.5 & 19.3 & 0.026 \\
\hline AV Fistula (\%) & 76.8 & 77.1 & 76.4 & N.S. \\
\hline S-Albumin $\geq 35 \mathrm{~g} / \mathrm{L}$ & 89.7 & 95.4 & 81.8 & $<0.001$ \\
\hline Charlson comorbidity index & & & & $<0.001$ \\
\hline$<7$ & 44.5 & 39.1 & 52.1 & \\
\hline $7-12$ & 51.9 & 56.7 & 45.2 & \\
\hline$>12$ & 3.6 & 4.3 & 2.7 & \\
\hline Diabetes mellitus & 26 & 30 & 25 & N.S. \\
\hline Phosphorus $\leq 5.5 \mathrm{mg} / \mathrm{dL}$ & 82.0 & 87.5 & 74.2 & $<0.001$ \\
\hline Calcium $\leq 10.2 \mathrm{mg} / \mathrm{dL}$ & 98.1 & 98.0 & 98.2 & N.S. \\
\hline PTH 150-600 pg/mL & 53.9 & 52.1 & 56.4 & N.S. \\
\hline
\end{tabular}

${ }^{*}$ Chi-2 analysis between countries

$\mathrm{spKt} / \mathrm{V}>1.2$ and a urea reduction ratio (URR) $\geq 70 \%$ was achieved in almost all patients, but more often so in Portuguese patients that in Polish patients $(p=0.003$ and $p$ $<0.001$ respectively, Table 2). Mean weekly treatment time was 724 (53) min in Portugal and 737 (55) min in Poland $(p<0.001)$ and the prescribed dialysis blood flow rate $(\mathrm{Qb})$ and the corresponding treated blood volume per dialysis session were both significantly higher in 
patients in facilities in Portugal than in patients in Poland $(p<0.001$ for both comparisons, Table 1 and Table 2).

\section{Renal anemia}

The mean $\mathrm{Hb}$ was similar in patients treated in units in Portugal (11.0 (1.3) g/dL) and in Poland (11.0 (1.3) g/dL) and the proportion of patients within the recommended KDIGO anemia target of $\mathrm{Hb} 10-12 \mathrm{~g} / \mathrm{dL}$ was also similar (66 and 70\% respectively, Table 1, Table 2 and Fig. 1). $78.3 \%$ of patients in Portugal received ESA compared to $73.7 \%$ in Poland (NS, Table 2). The weekly ESA dose corrected for epoetin/darbepoetin $(\times 250)$ was significantly higher 5154 (6077) U in HD patients in Portugal as compared to those in Poland (3133 (3068) U, $p<0.001)$. The route of administration of ESA was also different with more IV administration in Portugal (Table 2). There were no significant differences in the prescription of different types of ESAs in the two countries. ERI was $6.23 \mathrm{IU} / \mathrm{kg} /(\mathrm{g} / \mathrm{dL})$ in all hemodialysis patients and significantly higher in patients in Portugal (7.53) compared to patients in Poland (4.42; $p<0.001)$. Multiple regression analysis of the ERI index using backward selection adjusting for age, dialysis vintage, $\mathrm{Kt} / \mathrm{V}$, serum albumin, Charlson comorbidity index and country (Poland vs Portugal) showed that the country had the highest impact on changes in ERI (beta value -3.462, $p<0.001)$.

In dialysis centers in Poland the use and monthly doses of IV iron were $35-72 \%$ higher than in Portugal during three consecutive months $(p<0.001$, Table 1$)$. TSAT and the percentage of patients with TSAT $\geq 20 \%$ and TSAT $>50 \%$ were all significantly higher $(p<0.001$ for all three comparisons) in patients treated in Poland (Table 1, Table 2 and Fig. 2) compared to those in Portugal. Furthermore, serum ferritin as well as the percentage of patients with serum ferritin $>800 \mu \mathrm{g} / \mathrm{L}$ were significantly higher $(p<0.001$ for both comparisons) in patients treated in Poland compared to those in Portugal (Table 1, Table 2 and Fig. 2).

We also analyzed the achievement of $\mathrm{Hb}$ targets in relation to gender in all 1247 patients (70\% of females were within $\mathrm{Hb}$ target vs $65 \%$ of males, NS) as well as in the respective country (Portugal, female vs male, $70 \%$ vs $63 \%$, NS and Poland $71 \%$ vs $68 \%$, NS).

In relation to vascular access use, $68 \%$ of all patients with an AVF had $\mathrm{Hb}$ between 10 and $12 \mathrm{~g} / \mathrm{dL}$ as compared to $64 \%$ of all patients with a central venous catheter (CVC, NS). Comparisons between countries showed that $68 \%$ vs $69 \%$ of patients with an AVF in units in Poland and Portugal, respectively, achieved $\mathrm{Hb}$ within KDIGO targets (NS). However, among patients with a CVC significantly more patients in Poland (74\%) had $\mathrm{Hb}$ between 10 and $12 \mathrm{~g} / \mathrm{dL}$ compared to corresponding patients in facilities in Portugal $(48 \%, p<0.001)$.

\section{Correlations, multiple regression and logistic regression analysis}

Correlation analysis (Table 3) showed significant negative correlations between $\mathrm{Hb}$ and ferritin in all patients (Pearson correlation coefficient, $r=-0.13, p<0.01$ ), in patients in units in Portugal $(r=-0.22, p<0.01)$ but not in Poland (NS). There were no significant correlations between $\mathrm{Hb}$ and TSAT in all patients or in the respective country. Furthermore, we observed significant negative correlations between $\mathrm{Hb}$ and the corrected

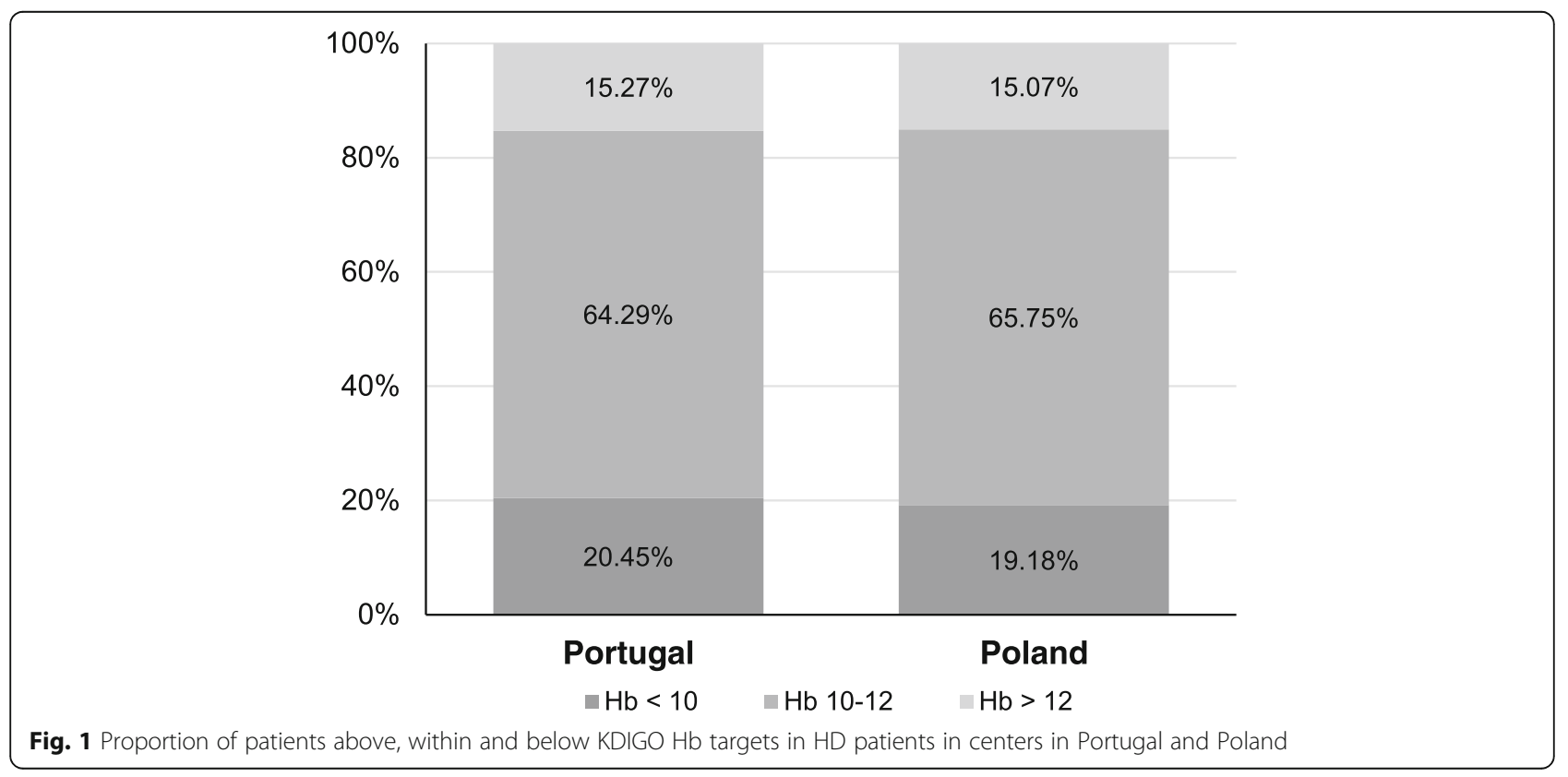




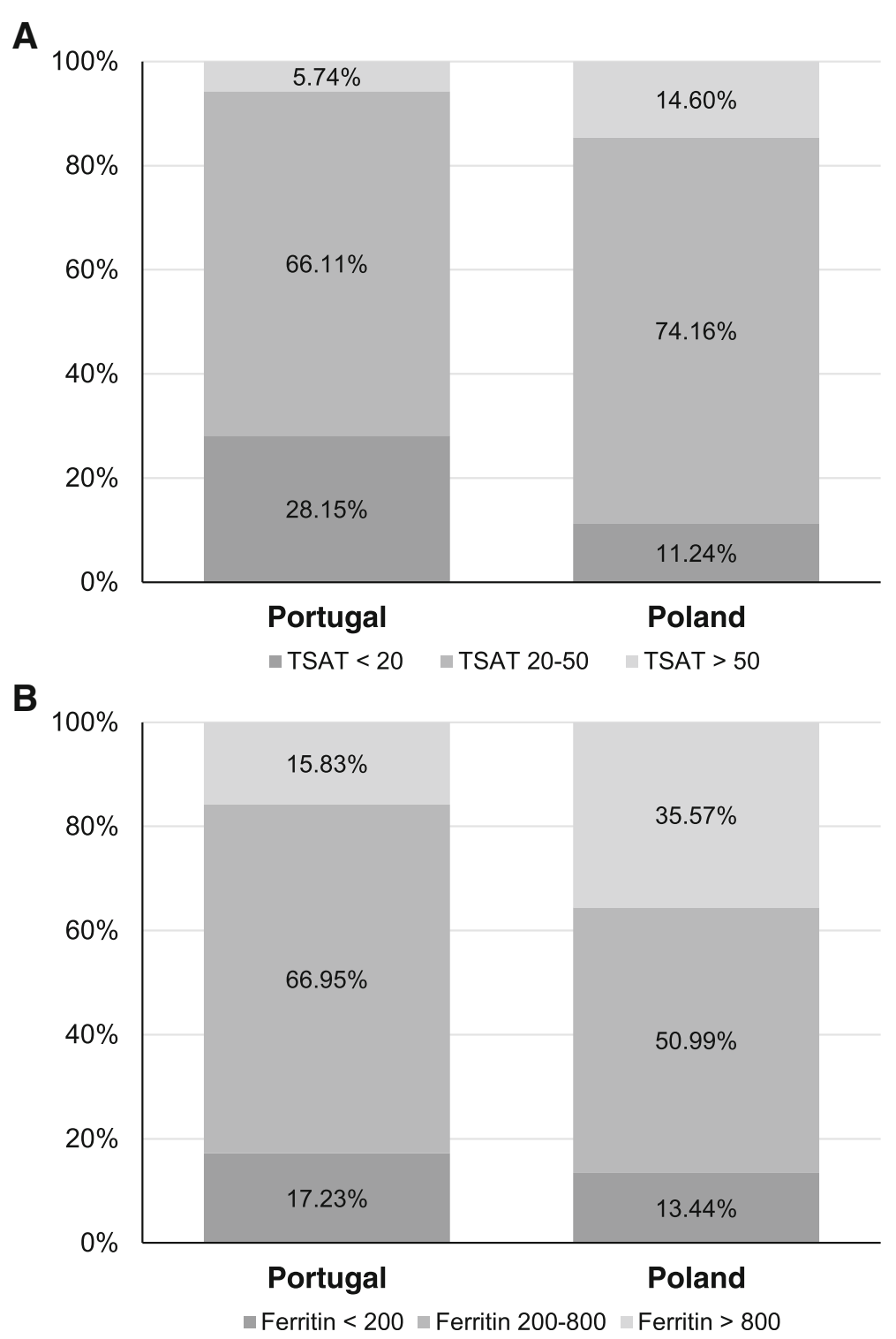

Fig. 2 Proportion of patients above, within and below KDIGO TSAT (a) and ferritin (b) targets in HD patients in centers in Portugal and Poland

(epoietin/darbepoietin) weekly dose of ESA in all patients $(r=-0.27, p<0.01)$ as well as in patients in centers in Portugal $(r=-0.25, p<0.01)$ and Poland $(r=-0.38$, $p<0.01)$. Taken together these findings are examples of confounding by treatment indication. Ferritin is also a marker of systemic inflammation and patients who are hyporesponsive to ESA-for example, due to malnutrition or inflammation-are often prescribed higher doses of ESA to achieve treatment targets in clinical practice.

Multiple regression (Table 4) of the effect on $\mathrm{Hb}$ (beta value) including age, gender, BMI, TSAT, ferritin, albumin and PTH in the analysis showed that ferritin had the strongest influence on $\mathrm{Hb}$ and that the effect on $\mathrm{Hb}$ is $-0.004(p<0.001)$. Subsequent logistic regression showed an odds ratio of $1.521(p<0.001)$ for ferritin $200-800 \mu \mathrm{g} / \mathrm{L}$ to achieve $\mathrm{Hb}$ within target $(10-12 \mathrm{~g} / \mathrm{dL})$. This association was strongest in patients treated at the centers in Portugal (odds ratio 1.865, $p<0.001$, Table 4) but not so in patients in Poland. Thus, with ferritin within KDIGO recommended ranges of $200-800 \mu \mathrm{g} / \mathrm{L}$ the odds for an $\mathrm{Hb}$ within guidelines increases significantly.

\section{Mortality}

We also studied gross and cause-specific mortality over 1 year in the respective country and at all dialysis centers within countries. One-year gross mortality was $16 \%$ in Poland and $13 \%$ in Portugal (NS); there were no significant differences in one-year mortality between centers in 
the respective country. There were also no differences in cause specific mortality (cardio- and cerebrovascular, infectious and malignancy) between countries (Fig. 3).

\section{Discussion}

The most important clinical finding of this large multicenter European cross-sectional analysis of all prevalent patients treated at 12 hemodialysis units in Portugal and Poland is that the KDIGO targets for the treatment of renal anemia in hemodialysis were achieved in both countries, but through different clinical practices and strategies. The $\mathrm{Hb}$ concentration was similar between countries and the proportion of patients within KDIGO target range was $69.5 \%$ in Poland and $65.8 \%$ in Portugal. The prescribed monthly doses of iron were $35-72 \%$ higher in dialysis facilities in Poland as compared to those in Portugal ( $p$ $<0.001$ ). Consequently, the ferritin and TSAT levels and the proportion of HD patients with a TSAT $>20$ and $>50 \%$ were both significantly higher in HD patients in centers in Poland (88.8 and 14.6\%) than in Portugal (76.3 and $5.7 \%$, respectively). In addition, significantly more patients in units in Poland had a ferritin concentration $>800 \mu \mathrm{g} / \mathrm{L}$ (35.6\%) compared to those in Portugal (15.8\%). By contrast, the prescribed ESA doses were $65 \%$ higher in HD patients in dialysis facilities in Portugal (5154 U) than in Poland (3133 U). Multiple and logistic regression analyses showed that with ferritin within KDIGO recommended ranges of $200-800 \mu \mathrm{g} / \mathrm{L}$ the odds for $\mathrm{Hb}$ within target range increases significantly. Taken together, both treatment traditions and socioeconomic factors seem to play a role in how anemia is managed in these facilities.

The optimal treatment algorithm for iron therapy and ESA use in anemic HD patients has so far not been established. Many would agree that in clinical practice one should avoid prescribing disproportionately high ESA or iron doses to achieve internationally recommended $\mathrm{Hb}$ targets, particularly in patients with significant comorbidity and/or ESA resistance. There were some differences in patient demographics and practices between patients in the clinics in Poland and Portugal in the present study. HD patients in facilities in Portugal were older and had a longer dialysis vintage, while more patients had diabetes and a high Charlson comorbidity index, all indicating a larger comorbidity burden than in

Table 3 Analyses of correlation ( $r=$ Pearson correlation coefficient) between achieved $\mathrm{Hb}$ and ferritin, TSAT and weekly dose of ESA in all patients and in Portugal and Poland respectively

\begin{tabular}{llll}
\hline & All & Portugal & Poland \\
\hline Hb vs Ferritin & $-0.125^{* *}$ & $-0.222^{* *}$ & -0.078 \\
$\mathrm{Hb}$ vs TSAT & 0.041 & 0.028 & 0.046 \\
$\mathrm{Hb}$ vs corrected weekly dose of ESA & $-0.271^{* *}$ & $-0.250^{* *}$ & $-0.384^{* *}$ \\
${ }^{* *} p<0.01$ & & &
\end{tabular}

Table 4 Multiple (a) and logistic (b) regression analysis of effects on $\mathrm{Hb} \mathrm{g} / \mathrm{dL}$ and the recommended $\mathrm{Hb}$ target of 10-12 $\mathrm{g} / \mathrm{dL}$

\begin{tabular}{|c|c|c|c|}
\hline & All & Portugal & Poland \\
\hline \multicolumn{4}{|c|}{$\begin{array}{l}\text { (a) Multiple regression analysis of effect of the respective variable on } \mathrm{Hb} \\
\text { in all patients and in Portugal and Poland, respectively }\end{array}$} \\
\hline & Beta value $(p)$ & Beta value $(p)$ & Beta value $(p)$ \\
\hline Age & 0.002 (NS) & 0.002 (NS) & 0.006 (NS) \\
\hline Gender & $-0.166(0.024)$ & $-0.196(0.035)$ & -0.068 (NS) \\
\hline BMl & 0.006 (NS) & -0.007 (NS) & $0.009(0.029)$ \\
\hline TSAT & $0.008(0.002)$ & $0.011(0.005)$ & 0.006 (NS) \\
\hline Ferritin & $\begin{array}{l}-0.0004 \\
(<0.001)\end{array}$ & $\begin{array}{l}-0.001 \\
(<0.001)\end{array}$ & $\begin{array}{l}0.0002 \\
(<0.001)\end{array}$ \\
\hline Albumin & $0.005(0.018)$ & $\begin{array}{l}0.070 \\
(<0.001)\end{array}$ & $0.004(<0.001)$ \\
\hline PTH & $\begin{array}{l}0.0003 \\
(<0.001)\end{array}$ & $0.0002(0.026)$ & $\begin{array}{l}0.0003 \\
(<0.001)\end{array}$ \\
\hline
\end{tabular}

(b) Logistic regression analysis with $\mathrm{Hb} 10-12 \mathrm{~g} / \mathrm{dL}$ as effect measure

\begin{tabular}{|c|c|c|c|}
\hline & Odds ratio $(p)$ & Odds ratio $(p)$ & Odds ratio $(p)$ \\
\hline Age (years) & 1.005 (N.S.) & 0.991 (N.S.) & $1.027(<0.001)$ \\
\hline Gender (M/F) & 1.267 (N.S.) & 1.337 (N.S.) & 1.098 (N.S.) \\
\hline $\mathrm{BMI}\left(\mathrm{kg} / \mathrm{m}^{2}\right)$ & 0.995 (N.S.) & 0.987 (N.S.) & 0.988 (N.S.) \\
\hline Albumin (> $35 \mathrm{~g} / \mathrm{dL}$ ) & 1.444 (N.S.) & $1.314(0.042)$ & 1.498 (N.S.) \\
\hline TSAT (20\%-50\%) & $1.438(0.008)$ & 1.314 (N.S.) & 1.498 (N.S.) \\
\hline $\begin{array}{l}\text { Ferritin }(200-800 \\
\mu \mathrm{g} / \mathrm{L})\end{array}$ & $1.521(0.001)$ & $\begin{array}{l}1.865 \\
(<0.001)\end{array}$ & 1.341 (N.S.) \\
\hline PTH (150-600 pg/mL) & 0.921 (N.S.) & 0.967 (N.S.) & 0.806 (N.S.) \\
\hline
\end{tabular}

patients in units in Poland. Despite this, significantly more patients in centers in Portugal had a serum albu$\min >35 \mathrm{~g} / \mathrm{L}$ and the use of a CVC was less frequent than in units in Poland.

The Optimal Renal Anemia Management Assessment (ORAMA) trial, published a decade ago [20], prospectively examined the impact of implementing anemia guidelines on outcomes relating to the management of renal anemia [21]. Results of the study showed that hemoglobin values were significantly higher in HD patients in Western Europe than those in Eastern Europe. While these findings suggested that Eastern European patients were being treated to lower $\mathrm{Hb}$ target levels at the time of the study, to our knowledge there are no recent European updates on this issue.

Several observational studies have shown that anemia in HD patients is associated with an increased risk of cerebro- and cardiovascular events, hospitalization and mortality [1, 2, 22]. However, given that renal anemia often is a marker of comorbidity, a cause-effect relationship has not yet been proven. Concerns about correcting anemia with high doses of ESA in CKD have been raised [5-7]. The TREAT study showed an increased cardiovascular risk with ESA use at high $\mathrm{Hb}$ values [7]. 


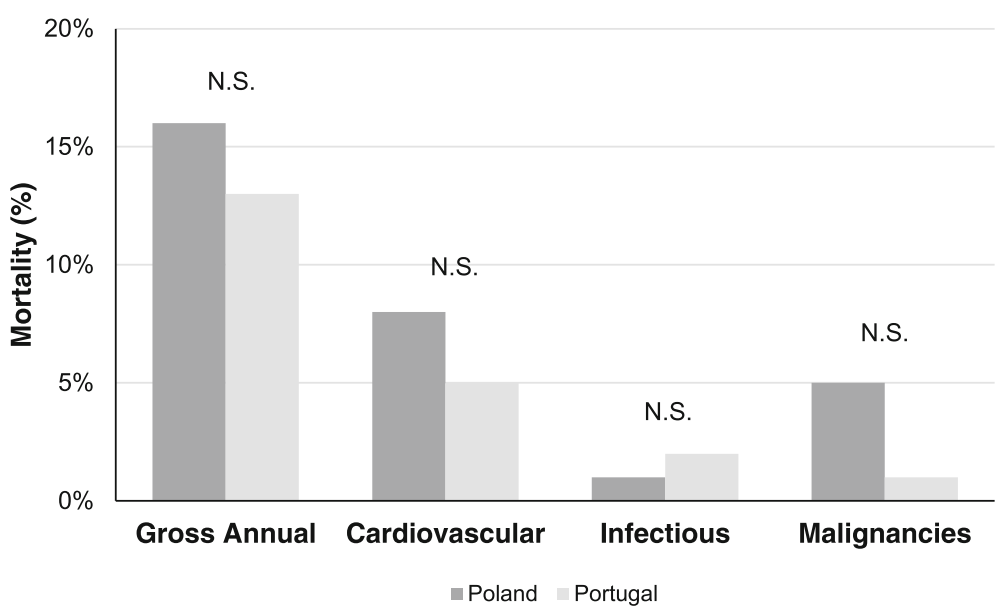

Fig. 3 Gross annual mortality and cause specific mortality (\%) in patients treated in Portugal and Poland

Randomization to the high $\mathrm{Hb}$ target group had a no effect on the primary composite cardiovascular end point, but a higher risk of venous and arterial thromboembolic events and stroke was observed, the latter unrelated to mean arterial blood pressure. Recently, a study of a large cohort of incident Spanish HD patients revealed a dose-dependent relationship between ESA dose and mortality risk: higher ESA doses were associated with a higher mortality, despite adjustments for potential confounders, including $\mathrm{Hb}$ and covariates related to ESA hyporesponsiveness [23]. In the present study, patients in Portugal had significantly higher ESA doses, but one-year gross and cause-specific mortality was similar (13\%) to that in Poland (16\%).

In the present study, both treatment strategies-focusing on either higher ESA doses $(+65 \%)$ with modest doses of iron, or a higher prescription of iron $(+35 \%-$ $72 \%$ per month) with less ESA requirement-resulted in $\mathrm{Hb}$ values within KDIGO guideline targets in the majority of patients. ESA hyporesponsiveness is common among dialysis patients, affecting up to $10 \%$ of patients with renal disease receiving ESA [24]. Iron deficiency, infection/inflammation, and inadequate dialysis are the most common cause of hyporesponsiveness [24]. In the present study, the ERI was significantly higher in patients treated in Portugal compared to patients treated in Poland. A recent large observational study showed that patients treated with HDF had significantly lower ERI, but that this study was limited to patients treated with intravenous erythropoietin [25]. The type of ESA prescribed was similar in our study, but in facilities in Portugal ESA was more frequently administered intravenously. The impact of route of administration on ESA dose requirements and responsiveness have been the subject of numerous studies, but so far no consensus has been reached. A recent evaluation of 24,957 patients receiving HD between 2011 and 2014 revealed no difference in ESA dose between subcutaneous (SC) and IV administration, despite an increasing proportion of patients receiving SC [23]. Furthermore, higher doses of ESA were associated with an increased risk of hospital admissions and mortality, with no differences between SC and IV routes of administration [26].

There is general consensus that iron therapy should be prescribed for HD patients who are iron deficient and may increase $\mathrm{Hb}$ values, delay the need for ESA therapy, and also reduce ESA requirements once therapy is initiated [27]. Both TSAT and ferritin have their shortcomings as measures with which to assess iron status and guide iron therapy in HD patients. TSAT and ferritin values generally considered to be indicative of iron deficiency are higher for patients on HD than for the general population due to the presence of inflammation [28]. There is also debate on the safety and efficacy of IV iron therapy, particularly for those patients who already have high serum ferritin levels. Infusion of iron in HD patients may overwhelm the capacity of the iron binding proteins, resulting in the presence of free iron in the circulation and/or to increase iron stores. Indeed, previous studies have shown that after IV iron injection in HD patients there is a transient increase in oxidative stress, as evidenced by an increase in plasma lipid peroxidation and oxidative modification of proteins [15]. Currently, there is no clear evidence to support a specific "safe" upper limit for serum ferritin levels but KDIGO guidelines recommend not exceeding a TSAT of $30 \%$ and serum ferritin of $500 \mathrm{ng} / \mathrm{mL}$ during iron therapy [19].

Large controlled clinical trials assessing the impact of more aggressive iron therapy on clinical outcomes have so far not been conducted, and observational studies have yielded inconsistent results. A study by Miskulin et al. [29] assessed 14,078 patients initiating dialysis in the 
US between 2003 and 2008 and showed that receipt of $\leq 1050 \mathrm{mg}$ intravenous iron in 3 months or $2100 \mathrm{mg}$ in 6 months was not associated with increased risk of all-cause, cardiovascular, or infection-related mortality. The same group [30] observed no consistent association between IV iron dose and risk for all-cause, cardiovascular, or infectious hospitalizations, even among patients receiving iron doses exceeding $2100 \mathrm{mg}$ over a period of 6 months. A new multicenter observational study of the safety of IV iron supplementation in incident HD patients showed that larger iron doses infused over time were not associated with mortality, after adjusting for potential confounding factors [31]. Furthermore, a recent systematic review and meta-analysis of 7 randomized controlled trials and 15 observational studies including more than 140,000 patients treated with HD, found no evidence of increased risk of infection, cardiovascular events, hospitalizations, or mortality with the use of higher-dose IV iron compared with lower doses [32]. Together these findings suggest that higher doses of IV iron prescribed in the course of routine anemia management in HD patients may not be associated with substantial harm, although additional randomized trials will be needed to confirm these findings.

The strength of this study is that it included all prevalent patients in all DaVita HD facilities in two European countries that previously have not been part of the DOPPS analyses, thus representing a "real world" clinical experience of modern Western and Eastern European renal anemia practice in HD. Such real-world analyses allow us to evaluate existing paradigms of care and inform the design of new treatment options. Our study has several limitations. First, this was an observational, cross-sectional study design and was reliant on aggregated data: thus, we were unable to estimate the relative causal contributions of changes in IV iron or ESA dose to serum ferritin. Second, we were unable to make risk assessments for hospitalizations and mortality since we lack individual data on these issues. Third, we do not have data on accumulated iron doses over longer periods of time in each patient. An individual patient may, over time, be given a combination of low- or high-dose iron or ESA therapies based on monthly laboratory parameters such as $\mathrm{Hb}$, TSAT and ferritin.

\section{Conclusions}

In conclusion, the present international multicenter study analyzed clinical practices and treatment strategies to correct renal anemia in 1247 prevalent HD patients in 12 dialysis centers in two European countries that previously have not been included in the global DOPPS analyses. The KDIGO hemodialysis anemia target was reached in patients treated at the dialysis centers in both Portugal and Poland, however by two different treatment strategies. Since mortality was similar in the centers, our findings suggest that higher doses of IV iron prescribed for HD patients during in routine clinical practice may not be associated with significant harm. However, meticulously performed randomized controlled trials are needed to provide decisive evidence of iron safety.

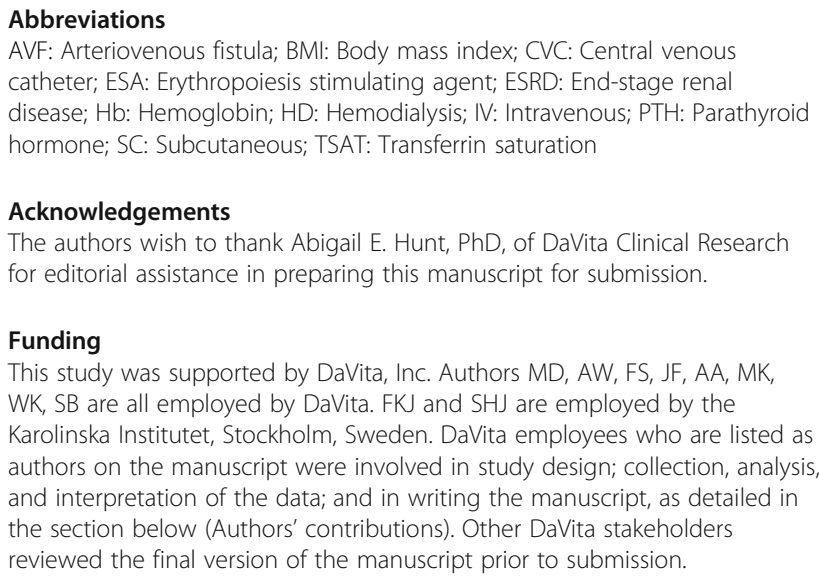

Availability of data and materials

Data used in this study were derived from the proprietary electronic health records database of a large dialysis provider and are not publicly available.

Authors' contributions

All authors contributed to the design of the study and interpretation of the results. Statistical analyses were performed by SHJ and FKJ. All authors contributed to the development of this manuscript and approved the final version for submission.

\section{Ethics approval and consent to participate}

The study was approved by the regional Ethics Committee at the Karolinska Institutet, Stockholm, Sweden. This study was a retrospective analysis of statistically deidentified data; informed consent was not required.

Consent for publication

not applicable.

\section{Competing interests}

WK has received speaker fees from Boehringer Ingelheim, Hexal, Profil Deutschland, IAD, Sanofi Aventis, Astra Zeneca, Amgen, and Abbvie. All other authors have no competing interests to declare.

\section{Publisher's Note}

Springer Nature remains neutral with regard to jurisdictional claims in published maps and institutional affiliations.

\section{Author details}

${ }^{1}$ DaVita Poland, Krakow, Poland. ${ }^{2}$ DaVita Portugal, Lisbon, Portugal. ${ }^{3}$ Nephrology Department, Hospital Santa Cruz, Carnaxide, Portugal. ${ }^{4}$ School of Medicine, University of Lisbon, Lisbon, Portugal. ${ }^{5}$ Department of Nephrology, São João Hospital Center, Porto, Portugal. ${ }^{6}$ School of Medicine, University of Porto, Porto, Portugal. 'DaVita Saudi Arabia, Riyadh, Saudi Arabia. ${ }^{8}$ King Saud University, Riyadh, Saudi Arabia. ${ }^{9}$ DaVita, Inc, Denver, CO, USA. ${ }^{10}$ DaVita Germany, Dusseldorf, Germany. ${ }^{11} \mathrm{Clinic}$ for Nephrology, Heinrich-Heine -University, Dusseldorf, Germany. ${ }^{12} 1$ st Department of Nephrology and Transplantation, Medical University of Bialystok, Bialystok, Poland. ${ }^{13}$ DaVita Poland, Bialystok, Poland. ${ }^{14}$ Unit for Medical Statistics, Department of Clinical Sciences, Karolinska Institutet, Danderyd University Hospital, Stockholm, Sweden. ${ }^{15}$ Division of Nephrology, Department of Clinical Sciences, Karolinska Institutet, Danderyd University Hospital, Stockholm, Sweden. 
Received: 13 August 2018 Accepted: 26 December 2018

Published online: 07 January 2019

\section{References}

1. Volkova N, Arab L. Evidence-based systematic literature review of hemoglobin/hematocrit and all-cause mortality in dialysis patients. Am J Kidney Dis. 2006:47:24-36.

2. Locatelli F, de Francisco A, Deray G, Fliser D, Armstrong G, Dougherty FC, Ehrhard P. Mortality and cardiovascular morbidity associated with haemoglobin levels: a pooled analysis of randomised controlled trials. Nephron Clin Pract. 2014;128:323-32.

3. Besarab A, Bolton WK, Browne JK, Egrie JC, Nissenson AR, Okamoto DM, Schwab SJ, Goodkin DA. The effects of normal as compared with low hematocrit values in patients with cardiac disease who are receiving hemodialysis and epoetin. N Engl J Med. 1998;339:584-90.

4. Drueke TB, Locatelli F, Clyne N, Eckardt KU, Macdougall IC, Tsakiris D, Burger $\mathrm{HU}$, Scherhag A. Normalization of hemoglobin level in patients with chronic kidney disease and anemia. N Engl J Med. 2006:355:2071-84.

5. Singh AK, Szczech L, Tang KL, Barnhart H, Sapp S, Wolfson M, Reddan D. Correction of anemia with epoetin alfa in chronic kidney disease. N Engl J Med. 2006;355:2085-98.

6. Szczech LA, Barnhart HX, Inrig JK, Reddan DN, Sapp S, Califf RM, Patel UD, Singh AK. Secondary analysis of the CHOIR trial epoetin-alpha dose and achieved hemoglobin outcomes. Kidney Int. 2008;74:791-8.

7. Pfeffer MA, Burdmann EA, Chen CY, Cooper ME, de Zeeuw D, Eckardt KU, Feyzi JM, Ivanovich $P$, Kewalramani R, Levey AS, et al. A trial of darbepoetin alfa in type 2 diabetes and chronic kidney disease. N Engl J Med. 2009;361: 2019-32.

8. Karaboyas A, Zee J, Morgenstern H, Nolen JG, Hakim R, Kalantar-Zadeh K, Zager P, Pisoni RL, Port FK, Robinson BM. Understanding the recent increase in ferritin levels in United States Dialysis patients: potential impact of changes in intravenous Iron and erythropoiesis-stimulating agent dosing. Clin J Am Soc Nephrol. 2015:10:1814-21.

9. Hasegawa T, Bragg-Gresham JL, Pisoni RL, Robinson BM, Fukuhara S, Akiba T, Saito A, Kurokawa K, Akizawa T. Changes in anemia management and hemoglobin levels following revision of a bundling policy to incorporate recombinant human erythropoietin. Kidney Int. 2011;79:340-6.

10. Nangaku M, Eckardt KU. Pathogenesis of renal anemia. Semin Nephrol. 2006;26:261-8.

11. Flint S, Taylor E, Beavis J, Becker GJ, Pedagogos E. Increased iron requirement in hemodialysis patients on antiplatelet agents or warfarin. Nephron Clin Pract. 2009;113:c38-45.

12. Fishbane S, Kowalski EA, Imbriano LJ, Maesaka JK. The evaluation of iron status in hemodialysis patients. J Am Soc Nephrol. 1996;7:2654-7.

13. Kalantar-Zadeh K, Hoffken B, Wunsch H, Fink H, Kleiner M, Luft FC. Diagnosis of iron deficiency anemia in renal failure patients during the posterythropoietin era. Am J Kidney Dis. 1995;26:292-9.

14. Rampton D, Folkersen J, Fishbane S, Hedenus M, Howaldt S, Locatelli F, Patni S, Szebeni J, Weiss G. Hypersensitivity reactions to intravenous iron: guidance for risk minimization and management. Haematologica. 2014;99:1671-6.

15. Tovbin D, Mazor D, Vorobiov M, Chaimovitz C, Meyerstein N. Induction of protein oxidation by intravenous iron in hemodialysis patients: role of inflammation. Am J Kidney Dis. 2002;40:1005-12.

16. Lee YK, Koo JR, Kim JK, Park II, Joo MH, Yoon JW, Noh JW, Vaziri ND. Effect of route of EPO administration on hemodialysis arteriovenous vascular access failure: a randomized controlled trial. Am J Kidney Dis. 2009;53:815-22.

17. Kalantar-Zadeh K, Lee GH, Miller JE, Streja E, Jing J, Robertson JA, Kovesdy CP. Predictors of hyporesponsiveness to erythropoiesis-stimulating agents in hemodialysis patients. Am J Kidney Dis. 2009;53:823-34.

18. Rossert J, Gassmann-Mayer C, Frei D, McClellan W. Prevalence and predictors of epoetin hyporesponsiveness in chronic kidney disease patients. Nephrol Dial Transplant. 2007;22:794-800

19. Kidney Disease. Improving global outcomes Anemia work group. KDIGO clinical practice guideline for anemia in chronic kidney disease. Kidney Int Suppl. 2012;2:279-335.

20. Wiecek A, Covic A, Locatelli F, Macdougall IC. Renal anemia: comparing current eastern and Western European management practice (ORAMA). Ren Fail. 2008;30:267-76.

21. European survey on anemia management (ESAM). Nephrol Dial Transplant. 1999;14:1-76.
22. Foley RN, Parfrey PS, Harnett JD, Kent GM, Murray DC, Barre PE. The impact of anemia on cardiomyopathy, morbidity, and and mortality in end-stage renal disease. Am J Kidney Dis. 1996;28:53-61.

23. Perez-Garcia R, Varas J, Cives A, Martin-Malo A, Aljama P, Ramos R, Pascual J, Stuard S, Canaud B, Merello Jl. Increased mortality in haemodialysis patients administered high doses of erythropoiesis-stimulating agents: a propensity score-matched analysis. Nephrol Dial Transplant. 2017;33(4):690-9.

24. van der Putten K, Braam B, Jie KE, Gaillard CA. Mechanisms of disease: erythropoietin resistance in patients with both heart and kidney failure. Nat Clin Pract Nephrol. 2008;4:47-57.

25. Marcelli D, Bayh I, Merello Jl, Ponce P, Heaton A, Kircelli F, Chazot C, Di Benedetto A, Marelli C, Ladanyi E, et al. Dynamics of the erythropoiesis stimulating agent resistance index in incident hemodiafiltration and highflux hemodialysis patients. Kidney Int. 2016;90:192-202.

26. Biggar $\mathrm{P}, \mathrm{Kim} \mathrm{GH}$. Treatment of renal anemia: erythropoiesis stimulating agents and beyond. Kidney Res Clin Pract. 2017;36:209-23.

27. Michels WM, Jaar BG, Ephraim PL, Liu Y, Miskulin DC, Tangri N, Crews DC, Scialla JJ, Shafi T, Sozio SM, et al. Intravenous iron administration strategies and anemia management in hemodialysis patients. Nephrol Dial Transplant. 2017;32:173-81.

28. Stancu S, Barsan L, Stanciu A, Mircescu G. Can the response to iron therapy be predicted in anemic nondialysis patients with chronic kidney disease? Clin J Am Soc Nephrol. 2010;5:409-16.

29. Miskulin DC, Tangri N, Bandeen-Roche K, Zhou J, McDermott A, Meyer KB, Ephraim PL, Michels WM, Jaar BG, Crews DC, et al. Intravenous iron exposure and mortality in patients on hemodialysis. Clin J Am Soc Nephrol. 2014;9:1930-9.

30. Tangri N, Miskulin DC, Zhou J, Bandeen-Roche K, Michels WM, Ephraim PL, McDermott A, Crews DC, Scialla JJ, Sozio SM, et al. Effect of intravenous iron use on hospitalizations in patients undergoing hemodialysis: a comparative effectiveness analysis from the DEcIDE-ESRD study. Nephrol Dial Transplant. 2015;30:667-75.

31. Varas J, Ramos R, Aljama P, Perez-Garcia R, Moreso F, Pinedo M, Ignacio Merello J, Stuard S, Canaud B, Martin-Malo A. Relationships between iron dose, hospitalizations and mortality in incident haemodialysis patients: a propensityscore matched approach. Nephrol Dial Transplant. 2018;33:160-70.

32. Hougen I, Collister D, Bourrier M, Ferguson T, Hochheim L, Komenda P, Rigatto C, Tangri N. Safety of intravenous Iron in Dialysis: a systematic review and meta-analysis. Clin J Am Soc Nephrol. 2018;13:457-67.

\section{Ready to submit your research? Choose BMC and benefit from:}

- fast, convenient online submission

- thorough peer review by experienced researchers in your field

- rapid publication on acceptance

- support for research data, including large and complex data types

- gold Open Access which fosters wider collaboration and increased citations

- maximum visibility for your research: over $100 \mathrm{M}$ website views per year

At BMC, research is always in progress.

Learn more biomedcentral.com/submissions 